\title{
Regulation of podocyte structure during the development of nephrotic syndrome
}

\begin{abstract}
Nephrotic syndrome is a common kidney disease seen in both children and adults. The clinical syndrome includes massive proteinuria, hypoalbuminemia, edema, and usually hypercholesterolemia. Development of these clinical changes is closely correlated with profound structural changes in glomerular epithelial cells, or
\end{abstract}

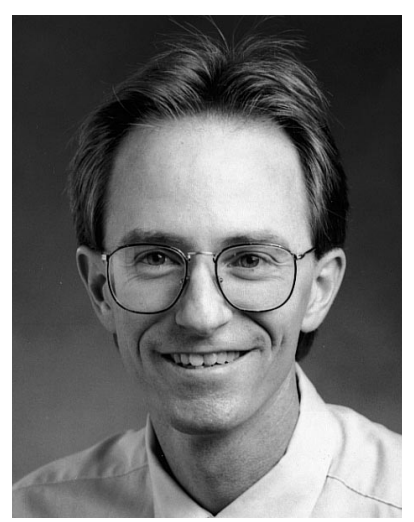

WiLLIAM E. SMOYER received his M.D. from the University of Florida prior to pursuing clinical and research training at the University of Texas Medical Branch, University of Pennsylvania, and Children's Hospital in Boston. He is currently Assistant Professor of Pediatrics at the University of Michigan. His major research interests include molecular mechanisms in nephrotic syndrome and podocyte cell biology.

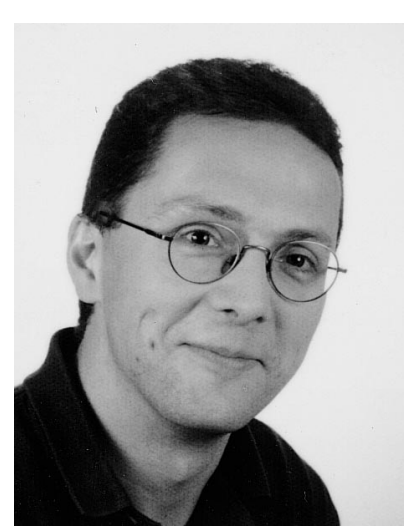

Peter Mundel

is at the Department of Anatomy and Cell Biology, University of Heidelberg. His major research interests include the cell biology of podocytes, regulation of process formation in nonneuronal cells, and the morphological basis of neuronal plasticity.

\section{W.E. Smoyer (匹)}

Division of Nephrology, Department of Pediatrics, Box 0684,

1150 W. Med. Ctr. Dr., University of Michigan, Ann Arbor, MI 48109-0684, USA

Peter Mundel

Institut für Anatomie und Zellbiologie, University of Heidelberg, Heidelberg, Germany podocytes, which together with the glomerular basement membrane and endothelium comprise the kidney's blood filtration barrier. Although relatively little is known about the cellular or molecular changes which occur within podocytes during the development of nephrotic syndrome, cytoskeletal proteins very likely play a central role in these changes since they are primarily responsible for the maintenance of cell structure in almost all cells. This review focuses on: (a) the structure and function of podocytes in both the normal state and during nephrotic syndrome and (b) the potential roles of several cytoskeleton-associated proteins identified in podocytes in the development of and/or recovery from the pathophysiological cytoskeletal changes which occur in podocytes during nephrotic syndrome.

Key words Cytoskeleton · $\alpha$-Actinin $\cdot$ hsp27 · Integrins Synaptopodin (pp44) $\cdot$ Foot process effacement

Abbreviations GBM Glomerular basement membrane * $h s p$ Heat shock protein $\cdot P A N$ Puromycin aminonucleoside

\section{Introduction}

Nephrotic syndrome is characterized clinically by the development of massive proteinuria, hypoalbuminemia, edema, and frequently hypercholesterolemia. The development of these clinical changes has been shown to be closely correlated with specific structural changes in the foot processes of glomerular visceral epithelial cells, or podocytes, which in part comprise the kidney's filtration barrier $[1,2]$. Nephrotic syndrome may be either primary, as in idiopathic nephrotic syndrome, or the result of another disease process, such as focal segmental glomerulosclerosis or IgM nephropathy (mesangial proliferative glomerulonephritis). Despite extensive studies in humans [3-9] and a well-established rat model of nephrotic syndrome [puromycin aminonucleoside (PAN) nephrosis] $[1,2,10-12]$, the pathogenesis of this disease is still not clear. A variety of pathogenic mechanisms, including im- 
munological processes, biochemical defects (induced by endogenous or exogenous factors), and hemodynamically induced glomerular injury can induce the nephrotic syndrome [13]. Because these various stimuli result in the development of a similar pattern of clinical and histological features, however, it is likely that there is a final common molecular pathway by which the normal regulation of podocyte foot process structure is disturbed during development of the nephrotic syndrome. Because cytoskeletal and cytoskeleton-associated proteins are generally responsible for the maintenance of cell structure, this review focuses on several cytoskeleton-associated proteins which are present in podocytes. The structure and function of podocytes in both the normal state and the nephrotic state are discussed, followed by a review of the available data on several potential regulators of podocyte structure during the development of nephrotic syndrome.

\section{Normal podocyte structure and function}

\section{Organization of the glomerular filtration barrier}

Filtration of the blood within the glomerular capillaries takes place in the glomerular filtration barrier. This barrier is composed of three components: a fenestrated endothelial cell layer, an extracellular glomerular basement membrane (GBM), and a glomerular epithelial cell (podocyte) layer with distal foot processes and interposed slit diaphragms (Fig. 1). The flow of glomerular filtrate from the capillary lumen to the urinary space is thought to follow a strictly extracellular route, passing across the fenestrated endothelium and GBM, then across the slit diaphragms which bridge adjacent foot processes just above the GBM, and finally through the filtration slits (spaces between foot processes) into the urinary space.

Although all kidney epithelial cells are attached to one another via tight junctions, the slit diaphragms connecting adjacent podocyte foot processes have been suggested to be modified tight junctions. This has been based on three key findings: (a) identification of the tight junction-associated protein, $\mathrm{ZO}-1$, on the cytoplasmic side of podocyte slit diaphragms [14], (b) evolution of the slit diaphragm from a tight junction during renal development [15], and (c) the tight junctionlike function of slit diaphragms to divide the podocyte apical and basolateral plasma membrane domains [15]. The total surface area of the slit diaphragms comprise only about $10 \%$ of the outer GBM surface. This reduces the actual capillary surface area for filtration approximately tenfold at the level of the podocytes.

The precise structure and composition of the slit diaphragm is largely unknown. In the early 1970s Rodewald and Karnovsky [16] published a model of the substructure of the slit diaphragm which was based on transmission electron microscopy results of tannic acid stained material. It consisted of rodlike units connected to a perpendicular central bar, forming a zipperlike pattern. The

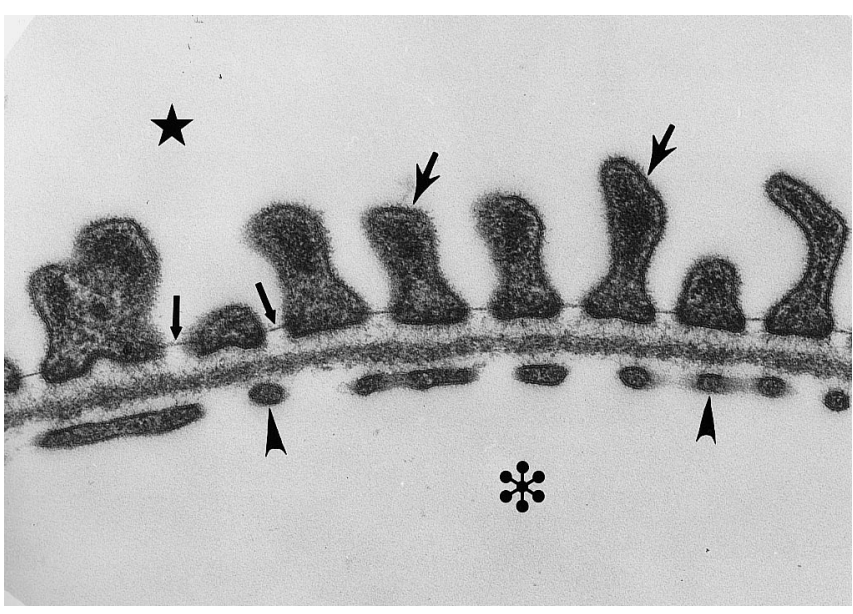

Fig. 1 Transmission electron micrograph showing the components of the glomerular filtration barrier. During normal glomerular filtration plasma water is filtered from the glomerular capillary lumen (asterisk) through fenestrated endothelial cell layer (arrowheads), across the GBM, through the slit diaphragms (small arrows) which bridge the filtration slits between adjacent podocyte foot processes (large arrows), and ultimately into the urinary space (star) where it enters the proximal tubular lumen. In the normal state the foot processes of the podocytes are tall and narrow and evenly spaced along the underlying GBM. A well-developed layer of negatively charged proteins, called the glycocalyx, can be seen as a fuzzy coating on the apical surface of the foot processes as they extend into the urinary space. $\times 52 \mid 000$

resulting rectangular pores had the approximate size of an albumin molecule. Based upon quick-freeze studies, doubts about the validity of this model have been raised $[17,18]$, but no convincing alternative has been reported. Only few data on the molecular identity of the slit diaphragm are available. The $\alpha$ - isoform of the ZO- 1 protein has been reported to be associated with the slit diaphragm in association with electron dense material at its insertion site into the sides of foot processes under both normal [14, 19] and pathological [20] conditions. From these data it was speculated that the slit diaphragm represents a modified tight junction [14, 19]. Orikasa and coworkers [21] and Kawachi et al. [22] also reported exclusive localization of a $51-\mathrm{kDa}$ protein defined by the monoclonal antibody 5-1-6 to the slit diaphragm. The identity and function of this protein, however, remain to be established.

\section{Basic structure of podocytes}

The spherical shape of the glomerular tuft is based in part on the structural support of the GBM, which forms the morphological basis of the individual capillaries of the tuft. While glomerular endothelial and mesangial cells are located inside the GBM, podocytes cover the outer aspect of the GBM (Fig. 2). Each podocyte generally serves more than one capillary, and each capillary is in turn covered by multiple podocytes, whose foot processes interdigitate on the capillary surface. Podocytes 


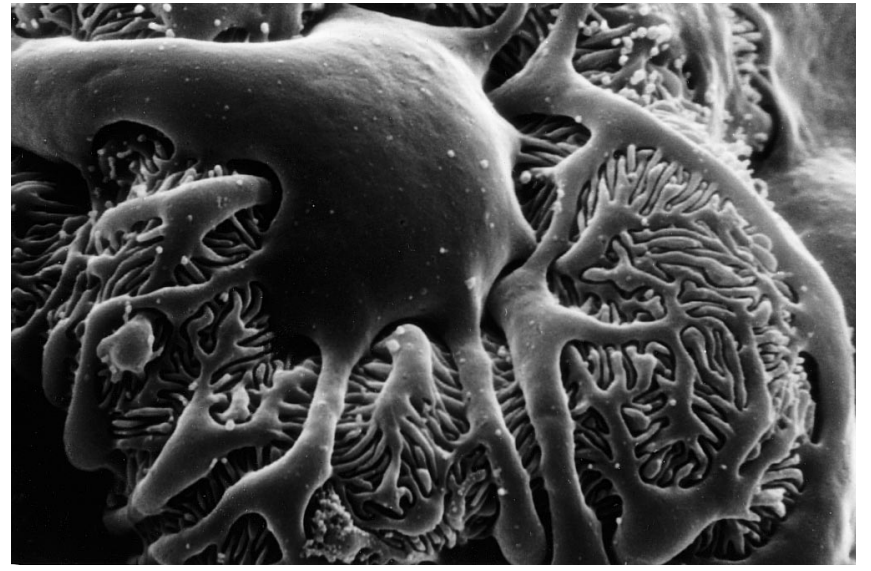

Fig. 2 Scanning electron micrograph of a podocyte viewed from the urinary space. The major processes can be seen extending out from the cell body and branching into more distal foot processes which surround a glomerular capillary loop passing below the cell body. In this photograph the foot processes of the podocyte can be seen interdigitating with foot processes from other podocytes. The resulting spaces between the foot processes are the filtration slits through which plasma water is filtered from the blood during urine production. $\times 10 \mid 500$

have several functions including GBM turnover, maintenance of the glomerular filtration barrier, regulation of glomerular filtration, and immunological functions [23].

Podocytes are unique cells with a complex cellular organization. With respect to their cellular architecture podocytes consist of three different segments: cell body, major processes, and foot processes. In general, cell bodies and major processes are not directly connected to the GBM but hang freely in the urinary space, fixed to the underlying capillaries only via attachment of their foot processes to the GBM (Fig. 2). As a consequence there is a sub-cell body space between the cell body and the foot processes. The major processes arise from the cell body which directly, or after additional branching, split into more distal foot processes. The foot processes decorate the outer aspect of the GBM, and establish the typical interdigitating pattern with foot processes of neighboring cells, leaving filtration slits between the foot processes (see Fig. 1). These filtration slits are bridged by the slit diaphragm, which is described in detail below. Interestingly, the foot processes originating from a single podocyte are never adjacent to each other along the GBM but are separated by the foot processes of another podocyte.

Podocytes are organized in a polarized fashion with an apical and basolateral membrane domain. The basolateral domain includes the sole plates of the foot processes, which are completely embedded in the GBM, and is separated from the apical domain by the slit diaphragm. Numerous coated pits and coated vesicles are frequently observed in normal foot processes and reflect the high rate of endocytosis known to occur in these cells [23]. The surface of the apical membrane domain, which is found above the slit diaphragm, contains a well-developed layer of negatively charged glycoproteins referred to as the glycocalyx. This negative charge causes charge repulsion of negatively charged proteins in the glomerular capillary and results in less filtration across the GBM of these proteins compared to similarly sized neutral proteins $[24,25]$. The glycocalyx constitutes the major negative charge of the glomerular filtration barrier and is thought to be essential in maintaining normal foot process structure. The overall negative charge results primarily from the presence of sialic acid and heparin sulfate residues on proteins located both in the GBM and on podocytes [26-28]. The glycocalyx is composed of podoendin [29] and several sialoglycoproteins including podocalyxin [30], GLEPP1 [31] SGP-115/107 [32] and others $[33,34]$. It appears to be of critical importance for the formation and preservation of the characteristic cellular architecture of podocytes [15, 35], and may prevent attachment of podocytes to the parietal epithelium of Bowman's capsule.

Only limited data are available concerning the molecular identity of the sialoglycoproteins which comprise the glycocalyx. Kershaw et al. [36] recently reported the cloning of a cDNA encoding for the rabbit form of podocalyxin, the major sialoglycoprotein in the glycocalyx. So far no homology with any published sequence has emerged. Among the specific proteins of the luminal membrane (reviewed in [23]), GLEPP 1 has been identified as a receptorlike transmembrane protein tyrosine phosphatase [37]. Although its function is not yet known, GLEPP I appears to be expressed only in the foot processes of podocytes and it has recently been shown to directly interact with podocalyxin [38]. In addition, decreased GLEPP I expression in glomeruli has recently been reported early in the course of glomerular inflammation and crescent formation in anti-GBM nephritis, suggesting it to be a sensitive indicator of glomerular injury [39]. Interestingly, the luminal membrane also contains cholesterol complexes which are thought to influence the fluidity and stability of podocyte cell shape [40] and appear to link cytoskeletal elements to the cell membrane [23]

\section{Developmental changes in podocyte structure}

During kidney development, podocytes undergo substantial phenotypic changes. Podocytes arise from precursor cells which are induced mesenchymal renal stem cells. Glomerular development usually is usually divided into four stages: renal vesicle, S-shaped body, capillary loop, and maturing glomeruli [41-43]. During the S-shaped body stage of glomerular development the presumptive podocytes acquire characteristics of epithelial cells, including apically located tight junctions [44, 45]. At this stage podocytes start to express podocalyxin [15] and the tight junction-associated protein ZO-1 [14]. The strong mitotic activity of these immature cells is reflected by the expression of the proliferation marker proliferatingcell nuclear antigen [46]. The transition from the immature podocyte precursor cells of the S-shaped body to the 


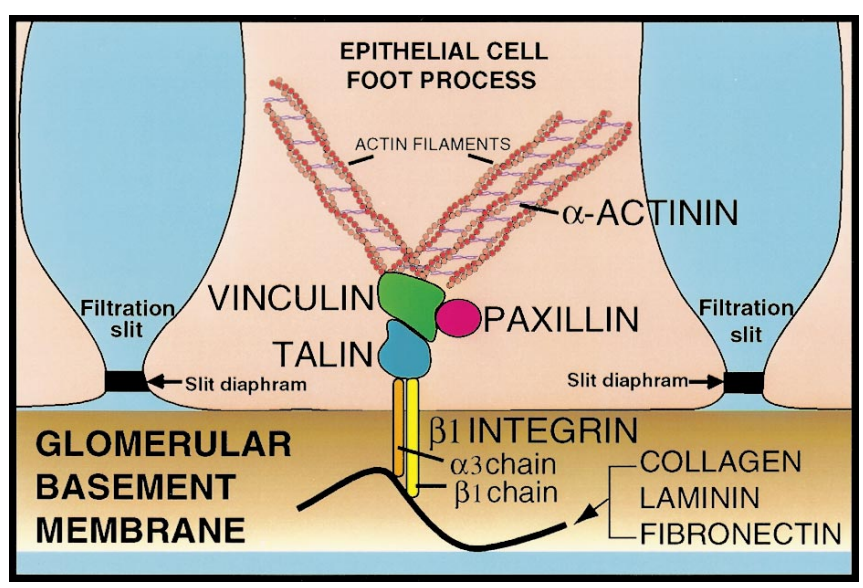

Fig. 3 Hypothetical cartoon of some of the cytoskeleton-associated proteins suggested to be involved in anchoring actin microfilaments to focal contacts at the base of podocyte foot processes. A high magnification view of a single podocyte foot process resting on the GBM reveals actin microfilaments converging on a macromolecular complex of proteins reported to be involved in focal contacts. This multimeric complex serves to anchor the actin cytoskeleton to the $\alpha_{3} \beta_{1}$-integrin heterodimer, which in turn anchors the entire foot process to extracellular matrix proteins in the underlying GBM. Regulation of the expression and/or interactions of these (and undoubtedly other) proteins is hypothesized to be critical for the maintenance of podocyte foot process structure

more mature cells of the capillary loop stage represents an epithelial to mesenchymal transdifferentiation and is accompanied by a loss of mitotic activity [46]. The cells begin to establish their characteristic complex cell architecture, including the formation of foot processes and the replacement of tight junctions by slit diaphragms which bridge the filtration slits between the developing foot processes [14]. During this time ZO-1 also moves from its apical location down to the level of the slit diaphragm where it becomes distributed in a dotted pattern along the filtration slits [14], and expression of a 51-kDa slit membrane-associated protein appears [22]. In addition, the formation of foot processes is accompanied by the appearance of synaptopodin (previously termed pp44), a podocyte-specific protein which colocalizes in mature podocytes with the actin filaments of podocyte foot processes [47].

The maturation of podocytes is also accompanied by stage-dependent changes in the expression of intermediate filament proteins. The induced renal mesenchymal cells of the vesicle stage express vimentin, an intermediate filament protein characteristic of mesenchymal cells, which disappears shortly thereafter [48]. Contradictory data have been presented, however, concerning the expression of intermediate filament proteins in human kidney. Holthöfer and coworkers reported no detectable vimentin or cytokeratin [48], whereas Oosterwijk et al. described the transient expression of cytokeratins 8 and 18 in the podocyte layer [49]. As the cells enter the capillary loop stage, vimentin reappears $[46,48]$ and synaptopodin (pp44) appears during the formation of foot processes [47].
These developmental changes in podocyte differentiation have important consequences for the mature podocyte. Several groups have provided evidence that mature podocytes cannot undergo cytokinesis in vivo [46, 50-55]. As described above, the transition of podocytes from the S-shaped body to the capillary loop stage and the formation of the typical cell architecture with cell processes represents a type of complex cell differentiation (similar to that seen in neurons) which seems to be incompatible with cell replication. Although certain stimuli such as basic fibroblast growth factor may induce podocytes to reenter the cell cycle and undergo mitosis or nuclear division, these cells remain unable to complete cell division [56]. An inability to divide may be the price that podocytes must pay for the development of their highly specialized cell architecture and attachment to the GBM. The molecular mechanism(s) underlying this inability to divide remain to be established, but a potential role for proliferation-associated proteins (cyclin-kinase inhibitors) in the podocyte response to injury has been reported [57]. Regardless of the mechanism, however, this inability to complete compensatory cell division in response to various pathophysiological conditions is of critical importance for the development of chronic renal failure $[54,55]$.

\section{Organization of the podocyte cytoskeleton}

In addition to mesangial cells, podocytes are crucial for providing structural support to the glomerular tuft. The segmentation of podocytes into cell body, major processes, and foot processes can also be observed at the level of the cytoskeleton. The intermediate filament proteins vimentin $[48,49,58,59]$ and desmin [60] (strain-dependent), which are typical of mesenchymal cells, are found in the cell body. To a smaller degree microtubules are also found in the cell body. In major processes the cytoskeleton is comprised primarily of microtubules which are interwoven with intermediate filament proteins. Microtubule-associated proteins such as MAP3 [61] and MAP4 [62] have also been described in association with these microtubules. In a recent study we have also noted the expression of MAP2 and tau in podocytes (Sanden et al., manuscript in preparation), both of which have binding sites for microtubules and for microfilaments (see below). In contrast to the cytoskeletal proteins in the cell body and major processes, foot processes are equipped with a microfilament-based contractile apparatus composed of actin, myosin-II, $\alpha$-actinin, talin, and vinculin [59]. This apparatus is anchored to focal contacts at the basal cell membrane (sole plate) of foot processes via an $\alpha_{3} \beta_{1}$-integrin complex, which in turn anchors the entire foot process to the underlying GBM [63-66]. Figure 3 shows a hypothetical cartoon of some of the cytoskeleton-associated proteins which have been suggested to be involved in the anchoring of actin microfilaments to focal contacts at the base of foot processes. In addition to these proteins we have recently reported that synaptopodin (pp44) is also associated with actin filaments in foot 

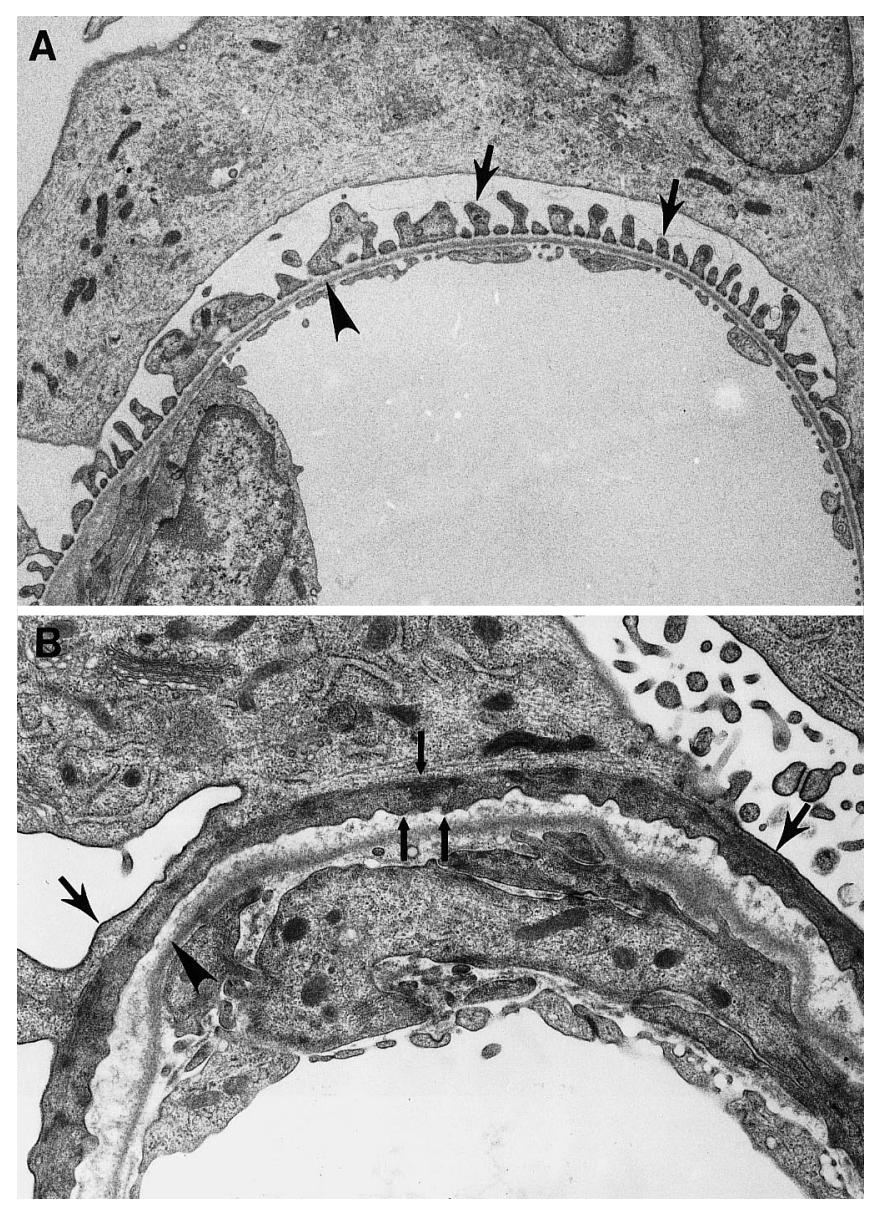

Fig. 4A, B Comparison of podocyte foot process structure in the normal state and during nephrotic syndrome. A Transmission electron micrograph of a glomerular capillary loop from a normal rat. Note the regular arrangement of delicate podocyte foot processes (arrows) attached to the GBM (arrowhead) around the periphery of the capillary. B A similar micrograph of a glomerular capillary loop from a rat with nephrotic syndrome (induced by injection of heterologous $\alpha$-GBM serum 7 days earlier). In contrast to the delicate arrangement of foot processes in the normal animal, the foot process (large arrows) have retracted and spread out (or effaced) along the GBM (arrowhead) to form a continuous band of cytoplasm. In severe disease individual foot processes may no longer be seen (as in this photograph), and the foot processes may detach from the underlying GBM (not shown). In this photograph a dense band of actin filaments (small arrows) can also be seen along the effaced foot processes running parallel to the GBM. $\times 17 \mid 300$

processes [47]. Molecular cloning of synaptopodin has revealed that it constitutes a novel class of proline-rich proteins, and that it appears to be a linear protein due to the equal distribution of proline residues along its entire sequence (Mundel et al., manuscript in preparation).

What is the relationship between the microtubular system of the major processes and the microfilament system of the foot processes? The microfilament bundles form arches between adjacent foot processes within each podocyte and are anchored in the sole plates of the foot processes, which in turn are firmly attached via the integrin complex to the GBM. The bends of these arches appear to be connected directly to the microtubules of the major processes. Using immunogold labeling we have found that the microtubule-associated protein tau, which has binding sites for both tubulin and actin, localizes exactly to the origin of the foot processes from the major processes. These results point to a possible role for tau in crosslinking the microtubular and microfilament systems of podocyte processes (Sanden et al., manuscript in preparation). The functional role of this complex cytoskeletal network has not yet been characterized. Based on the available evidence, however, we have recently suggested that the foot processes are involved in stabilizing the architecture of the tuft and counterbalancing the outward forces exerted on the capillary wall by the transmural glomerular filtration pressure gradient [23, 67].

\section{Podocyte Structure and Function During Nephrotic Syndrome}

Development of nephrotic syndrome is characterized by numerous morphological changes in podocytes. The most characteristic structural alteration is retraction and effacement (spreading) of the podocyte foot processes, resulting in the formation of a diffuse cytoplasmic sheet along the GBM (Fig. 4). Other structural changes include cell swelling, occurrence of occluding junctions with apical displacement of the slit diaphragms (located in the filtration slits between foot processes of adjacent podocytes), and frequently detachment of the podocyte from the underlying GBM [1, 2, 68-70]. Detachment of effaced foot processes from the GBM is generally considered the most severe structural manifestation of nephrotic syndrome. Several studies have now clearly demonstrated that detachment of the podocyte from the GBM results in leakage of protein across the GBM at the site of detachment [71-74]. Based on these findings podocytes appear to form a significant portion of the kidney's filtration barrier, and the proteinuria seen in nephrotic syndrome is now thought to result directly from the leakage of massive amounts of protein across the GBM at these sites of podocyte detachment.

In addition to dramatic changes in foot process structure during nephrotic syndrome, significant alterations also occur in the filtration slits and slit diaphragms. Foot process effacement results in a decrease in the filtration slit frequency along the GBM and has been associated with narrowing of the filtration slits and development of actual tight junctions between foot processes [20]. These structural alterations in the filtration barrier may act together to reduce overall glomerular filtration, a finding reported in human nephrotic syndrome [75]. Support for the importance of podocytes in the maintenance of the glomerular filtration barrier includes mathematical calculations which suggest that the filtration slits provide about $50 \%$ of the hydraulic resistance of the glomerular capillary wall, and studies showing induction of proteinuria following treatment of rats with an antibody directed primarily against a slit membrane-associated antigen 
[76]. Within the filtration slits the majority of the hydraulic resistance is thought to be provided by the slit diaphragms themselves [77].

Induction of foot process effacement by perfusing the kidney with the polycation protamine sulfate has been reported to cause apical displacement of the slit diaphragms and development of true tight junctions between foot processes [20]. Importantly, the ZO-1 protein colocalizes acutely with both the newly formed tight junctions and the displaced slit diaphragms [20] and is phosphorylated on tyrosine residues [78]. These findings suggest that phosphorylation of tight junction-associated proteins may be part of a signaling pathway responsible for slit diaphragm displacement and the formation of tight junctions in podocytes during foot process effacement.

The negative charge of the podocyte glycocalyx also appears to have a critical role in the regulation of podocyte foot process structure. Several studies have reported that infusion of polycations (protamine sulfate) into rats resulted in both neutralization of the negative surface charge and effacement of podocyte foot processes [79-83]. These changes occurred within 10-30 min and were largely reversible with subsequent infusions of the polyanion heparin. Induction of nephrotic syndrome in rats with PAN has been also reported in some [28, 84-86] but not all $[87,88]$ studies to be associated with reduced negative charge of the glomerular filtration barrier. In addition, these changes have been shown to be correlated with a reduction in the sialic acid content of podocalyxin [89]. Together these reports suggest that maintenance of the negative charges in the GBM and on podocytes is important for the maintenance of normal glomerular filtration and foot process structure, and that reduction in these negative charges may have an important role in the development of nephrotic syndrome.

Finally, despite the abundant evidence linking the development of nephrotic syndrome with structural changes in podocyte foot processes, transient proteinuria in the absence of any apparent changes in podocyte foot process structure or charge has also been reported following hydrogen peroxide infusion into the renal arteries of rats [90]. These findings have not yet been duplicated by others, and their significance remains unclear. To our knowledge, all other models of experimental nephrotic syndrome and all cases of nephrotic syndrome in humans have been associated with podocyte foot process effacement.

\section{Potential Regulators of Foot Process Effacement}

The sections above review normal podocyte structure and function and the characteristic changes which have previously been reported to occur in podocytes during development of nephrotic syndrome. Recently, however, several additional potential podocyte structural proteins have been identified which may prove to have important roles in the regulation of both normal podocyte structure and the cytoskeletal changes in podocytes which occur during development of foot process effacement in nephrotic syndrome. Significant alterations in the expression of some of these proteins either preceding or following foot process effacement further suggest that these proteins have important pathophysiological or reparative roles in nephrotic syndrome.

\section{$\alpha$-Actinin}

$\alpha$-Actinin is an actin-bundling protein thought to have an important role both in the loose crosslinking of actin filaments into contractile bundles and in helping to form the anchoring complex for the ends of actin stress fibers where they terminate on the plasma membrane at focal contacts [91]. Podocyte foot processes are known to contain high concentrations of actin [92, 93], and several reports have documented an abnormal distribution and disaggregation of podocyte actin microfilaments during the development of foot process effacement [69, 94, 95]. Concomitant redistribution of actin and $\alpha$-actinin in the podocytes of nephrotic rats has also been reported [96], and increased immunofluorescence staining of $\alpha$-actinin in podocytes has recently been noted during foot process effacement in nephrotoxic serum nephritis (Masugi nephritis) [97]. In addition, $\alpha$-actinin has been shown to bind to the cytoplasmic domain of the $\beta_{1}$-subunit of integrin molecules [98], which serve to attach the foot processes to the GBM, suggesting it may be important in anchoring podocyte actin microfilaments to integrins at the base of foot processes. These findings suggest that alterations in the expression and/or distribution of $\alpha$-actinin, or alterations in its interactions with other podocyte cytoskeletal proteins play an important role in the development of foot process effacement and nephrotic syndrome.

We have recently identified a significant transient increase in the expression of glomerular $\alpha$-actinin which precedes the development of foot process effacement in experimental nephrotic syndrome [99]. Using the PAN nephrosis rat model, in which massive proteinuria and diffuse foot process effacement typically develop within 5-7 days after injection, we found an early induction of $\alpha$-actinin on day 1 after injection, which returned to control levels by day 3 and remained normal thereafter. Immunolocalization studies localized the glomerular $\alpha$-actinin almost exclusively to podocyte foot processes. Identification of these changes lends further support to a possible pathogenic role for dysregulation of cytoskeletal and/or cytoskeleton-associated proteins in the development of foot process effacement in nephrotic syndrome.

\section{hsp27}

Another molecule which might have an important role in the molecular regulation of podocyte foot process structure is the low molecular weight heat shock protein (hsp) 27 . We have recently identified high concentrations of 
hsp27 in the podocytes of normal rats [100]. The hsps comprise several families of intracellular proteins whose expression are increased in response to various cellular stresses, including heat and metabolic insults. These proteins are named by their sizes (i.e., hsp27, hsp60, hsp70, hsp90, hsp100) and have been reported to be involved in the assembly, folding, translocation, function, and degradation of intracellular proteins and protein complexes [101-103]. Although the majority of high molecular weight hsps (hsp60, 72, 90) have been identified in the kidney [104-109], very few reports have identified low molecular weight hsps (hsp27) in the kidney [110, 111], and its function in the kidney is unclear.

Although the exact functions of hsp27 are not yet known, suggested functions include involvement in resistance to thermal and metabolic stress, growth and differentiation, signal transduction, and functioning as a molecular chaperone [112-118]. Other studies have reported that hsp27 is an actin-associated protein [119] which inhibits actin polymerization in vitro [120], and that its actin polymerization-inhibiting activity is related to its state of phosphorylation [121, 122]. It has also been reported to be a component of a signal transduction pathway that may regulate actin microfilament dynamics [123] and one pathway has now been identified whereby hsp27 is phosphorylated as a result of activation of a protein kinase cascade by the cytokine interleukin-1 $\alpha$ [124]. Taken together these findings suggest that hsp27 may play an important role in the maintenance of the kidney's filtration barrier and normal podocyte foot process structure by regulation of actin microfilament dynamics in the foot processes.

In an effort to further define the role of hsp27 in the regulation of foot process structure we analyzed changes in glomerular hsp27 expression and phosphorylation during the development of podocyte foot process effacement in experimental nephrotic syndrome. Following a single injection of PAN rats developed diffuse podocyte foot process effacement within 7 days after injection. This was associated with a significant increase in both glomerular hsp27 expression $(87 \pm 2 \%)$ and phosphorylation $(101 \pm 32 \%)$ at day 10 after injection [100]. Immunolocalization of hsp27 within the glomeruli revealed that it was almost completely restricted to podocytes. Together with the identification of hsp27 in normal podocytes, these findings suggest that hsp27 may also have an important role in regulating the pathophysiological cytoskeletal changes which occur in podocytes during development of nephrotic syndrome.

Induction of hsp27 in podocytes during development of foot process effacement suggests three possible functions for this protein. (a) A pathophysiological stimulus might directly induce hsp27 expression and phosphorylation, resulting in disturbance of the delicate balance between actin polymerization and depolymerization within foot processes. Disruption of foot process cytoskeletal dynamics might then lead to alterations in foot process structure, and ultimately to foot process effacement and proteinuria. This sequence of events would support a pathophysiological role for hsp27 in the development of nephrotic syndrome. (b) In an alternative scenario the pathophysiological stimulus might induce foot process effacement directly, resulting in induction of hsp27 as a specific response to the altered distribution $[69,96]$ and disaggregation [95] of actin microfilaments seen during foot process effacement. In this sequence of events hsp27 would have a role in the reparative or protective response of the podocyte to cellular stress. This function for hsp27 has been demonstrated in cell culture systems where transfection of hsp27 cDNA into several cell types induced markedly enhanced resistance to oxidative, thermal, and metabolic stresses [112, 113, 125-127]. (c) Lastly, the pathophysiological stimulus might induce foot process effacement directly, resulting in induction of hsp27 expression and phosphorylation as a nonspecific podocyte response to a stress unrelated to the altered actin microfilaments associated with foot process effacement. Since significant induction of glomerular hsp27 did not develop until after the development of massive proteinuria and foot process effacement, the observed changes most strongly support a role for hsp27 in the podocyte response to cellular stress resulting from dysregulation of actin microfilaments in the foot processes. This is further supported by the recent finding that hsp27 redistributes from the podocyte cell body toward the more distal actin-rich foot processes during the development of foot process effacement (Smoyer et al., manuscript in preparation).

These changes in glomerular hsp27 expression appear to represent a generalized stress response of the podocyte during foot process effacement. We recently analyzed glomerular hsp27 expression using an alternate animal model of nephrotic syndrome (nephrotoxic serum nephritis or Masugi nephritis) and found that during development of foot process effacement glomerular hsp27 is induced even more strongly than in PAN nephrosis (Smoyer et al., manuscript in preparation). In contrast to the PAN studies where nephrotic syndrome is thought to result from toxic injury to podocytes, Masugi nephritis is induced by injection of heterologous anti-GBM antibody and results in a proliferative glomerulonephritis characterized by an influx of polymorphonuclear leukocytes and mononuclear cells [128-131]. These similar responses by the podocyte in pathophysiologically distinct models of nephrotic syndrome suggest that a variety of mechanisms (i.e., toxic, immunological, etc.) for the induction of nephrotic syndrome ultimately converge on a common molecular pathway which elicits a similar or identical stress response by podocytes during foot process effacement.

\section{Integrins}

Podocyte foot processes surround the GBM and the underlying endothelium, and together they form the blood filtration barrier which maintains selective permeability to proteins (see Fig. 1). Attachment of the podocyte cell 
membrane to the GBM occurs via binding of cell adhesion molecules, called integrins, to extracellular matrix proteins (e.g., laminin, collagen IV, fibronectin) in the GBM. Integrins are heterodimeric proteins, composed of a single $\alpha$-chain noncovalently linked to a single $\beta$ chain. The predominant integrin which has been identified on glomerular podocyte foot processes is the $\alpha_{3} / \beta_{1-}$ integrin $[63,132-135]$. The extracellular domain of the integrin interacts with the extracellular matrix of the GBM, while the cytoplasmic domain interacts with the cytoskeletal protein actin through a heteromeric complex of actin-associated proteins including talin, vinculin, $\alpha$ actinin, and paxillin $[59,78,98,132]$. These proteinprotein interactions are thought to be critical in maintaining podocyte foot process structure and attachment to the GBM.

Because of this role alterations in the expression and/or function of integrins have been suggested to have a potentially important role in proteinuric diseases such as nephrotic syndrome [136]. Although direct quantitation of changes in integrins during nephrotic syndrome has not been reported, there is strong indirect evidence suggesting a critical role for the glomerular $\alpha_{3}$-integrin subunit in the maintenance of podocyte foot process structure. Kreidberg et al. [137] recently analyzed transgenic mice homozygous for an $\alpha_{3}$-integrin subunit mutation (who died shortly after birth) and found extensive podocyte foot process effacement and disorganization of the GBM in the glomerular capillary loops. Additional studies by Adler et al. [138] have demonstrated increased albumin permeability of glomeruli and decreased adhesion of podocytes to GBM matrix components in vitro following incubation with an antibody directed against the $\beta_{1}$-integrin subunit. In these studies crosslinking of anti- $\beta_{1}$-integrin Fab fragments with a second antibody was necessary to induce albumin permeability, suggesting that crosslinking of $\beta_{1}$-integrin molecules on the surface of foot processes is a critical early event in the development of altered glomerular permeability. These investigators also reported that perfusion of rat kidneys with anti- $\beta_{1}$-integrin antibodies is capable of inducing modest proteinuria in vivo [139]. Descriptive studies in humans, however, have not identified significant changes in the glomerular expression of $\beta_{1}$-integrin in human nephrotic syndrome [64, 140].

Because of the apparent central role of $\alpha_{3} / \beta_{1}$-integrins in the maintenance of a normal glomerular filtration barrier via attachment of foot processes to the GBM we recently analyzed the glomerular expression of both the $\alpha_{3}$ and $\beta_{1}$-integrin subunits at several time points during development of foot process effacement and nephrotic syndrome. Our studies used the PAN rat model in which diffuse foot process effacement and massive proteinuria characteristically develop between 5-7 days following a single injection of PAN [141]. We found a significant increase in glomerular $\alpha_{3}$-integrin expression compared to control animals only at day 10 after PAN injection, clearly following the development of podocyte foot process effacement and nephrotic syndrome [99]. Since this protein is expressed in all three glomerular cell types (endothelial, mesangial, and podocytes) [132, 142], however, this induction of glomerular $\alpha_{3}$-integrin following foot process effacement cannot be clearly attributed to podocytes.

If these changes were in fact significantly restricted to podocytes, they might represent a reparative response of the podocyte to normalize its attachment to the GBM by increasing the expression of extracellular matrix-binding proteins. Interestingly, we did not observe similar significant changes in the glomerular expression of the $\beta_{1}$-integrin subunit either preceding or following the development of podocyte foot process effacement and nephrotic syndrome. This discrepancy might have resulted either from delayed induction of $\beta_{1}$-subunit compared to $\alpha_{3}$ subunit expression or from insensitivity of our assay to detect changes due to the higher basal expression of the $\beta_{1}$-integrin subunit in glomeruli. It is clearly possible that disruption of the physical interaction between the podocyte integrin extracellular domain and the GBM or between the integrin intracellular domain and the foot process cytoskeleton is in fact more important in the development of foot process effacement than alterations in integrin subunit expression.

\section{Summary}

Maintenance of the delicate structure of normal podocytes appears to be actively regulated and involves complex interactions between the extracellular matrix proteins of the GBM, the transmembrane integrins in podocyte foot processes, and numerous podocyte cytoskeletal proteins. Although nephrotic syndrome is a common kidney disease among adults and is among the most common kidney diseases seen in children, little is known about the cellular and molecular changes which occur within podocytes during the development of foot process effacement and nephrotic syndrome. Recent studies have identified several proteins expressed in podocytes which may have important roles in either induction of or recovery from the pathophysiological cytoskeletal changes in podocyte foot process structure observed during nephrotic syndrome. Early induction of $\alpha$-actinin may result in dysregulation of actin microfilament bundling in foot processes, resulting in disruption of normal foot process structure. In contrast, late induction of hsp27 may represent a stress response by podocytes to the actin disaggregation in foot processes which characterizes nephrotic syndrome. Finally, disturbances in the expression and/or interactions between the $\alpha_{3} / \beta_{1}$-integrin heterodimers and either extracellular GBM proteins or intracellular podocyte cytoskeletal proteins may have roles in either the development of or recovery from altered foot process structure.

Acknowledgements The authors thank Drs. Wilhelm Kriz and David Kershaw for their critical reviews of this manuscript. This work was supported in part by a grant from the National Kidney Foundation of Michigan to W.E.S. 


\section{References}

1. Ryan GP, Karnovsky MJ (1975) An ultrastructural study of the mechanisms of proteinuria in aminonucleoside nephrosis. Kidney Int 8:219-232

2. Caulfield JP, Reid JJ, Farquhar MG (1976) Alterations of the glomerular epithelium in acute aminonucleoside nephrosis. Evidence for formation of occluding junctions and epithelial cell detachment. Lab Invest 34:43-59

3. Levin M, Gascoine P, Turner MW, Barratt TM (1989) A highly cationic protein in plasma and urine of children with steroid-responsive nephrotic syndrome. Kidney Int 36:867-877

4. Schnaper HW, Aune TM (1985) Identification of the lymphokine soluble immune response suppressor in urine of nephrotic children. J Clin Invest 76:341-349

5. Schnaper HW, Aune TM (1987) Steroid-sensitive mechanism of soluble immune response suppressor production in steroid-responsive nephrotic syndrome. J Clin Invest 79: 257-264

6. Moorthy AV, Zimmerman SW, Burkholder PM (1976) Inhibition of lymphocyte blastogenesis by plasma of patients with minimal-change nephrotic syndrome. Lancet 1 : $1160-1162$

7. Sobel AT, Branellec AI, Blanc CJ, Lagrue GA (1977) Physicochemical characterization of a vascular permeability factor produced by Con-A-stimulated human lymphocytes. J Immunol 119:1230-1234

8. Lagrue G, Laurent J, Rostoker G (1989) Food allergy and idiopathic nephrotic syndrome. Kidney Int 36:S147-S151

9. Koyama A, Fujisaki M, Kobayashi M, Igarashi M, Narita M (1991) A glomerular permeability factor produced by human T cell hybridomas. Kidney Int 40:453-460

10. Klein DJ, Dehnel PJ, Oegema TR, Brown DM (1984) Alterations in proteoglycan metabolism in the nephrotic syndrome induced by the aminonucleoside of puromycin. Lab Invest 50:543-551

11. Hoyer JR, Ratte J, Potter A H, Michael AF (1972) Transfer of aminonucleoside nephrosis by renal transplantation. J Clin Invest 51:2777-2780

12. Nakamura T, Ebihara I, Shirato I, Tomino Y, Koide H (1991) Modulation of basement membrane component gene expression in glomeruli of aminonucleoside nephrosis. Lab Invest 64:640-647

13. Glassock RJ (1988) Pathogenesis of the nephrotic syndrome. In: Cameron JS, Glassock RJ (eds) The nephrotic syndrome. Dekker, New York, pp 163-192

14. Schnabel E, Anderson JM, Farquhar MG (1990) The tight junction protein ZO-1 is concentrated along slit diaphragms of the glomerular epithelium. J Cell Biol 111:1255-1263

15. Schnabel E, Dekan G, Miettinen A, Farquhar MG (1989) Biogenesis of podocalyxin - the major glomerular sialoglycoprotein in rat kidney. Eur J Cell Biol 48:313-326

16. Rodewald R, Karnovsky MJ (1974) Porous substructure of the glomerular slit diaphragm in the rat and mouse. $\mathrm{J}$ Cell Biol 60:423-433

17. Hora K, Ohno S, Oguchi H, Furukawa T, Furuta S (1990) Three-dimensional study of glomerular slit diaphragm by the quick-freezing and deep-etching replica method. Eur J Cell Biol 53:402-406

18. Ohno S, Hora K, Furukawa T, Oguchi H (1992) Ultrastuctural study of the glomerular slit diaphragm in fresh unfixed kidneys by a quick-freezing method. Virch Arch B Cell Pathol 61:351-358

19. Kurihara H, Anderson JM, Farquhar MG (1992) Diversity among tight junctions in rat kidney: glomerular slit diaphragms and endothelial junctions express only one isoform of the tight junction protein ZO-1. Proc Natl Acad Sci 89: 7075-7079

20. Kurihara H, Anderson JM, Kerjaschki D, Farquhar MG (1992) The altered glomerular filtration slits seen in puromycin aminonucleoside nephrosis and protamine sulfate-treated rats contain the tight junction protein ZO-1. Am J Pathol 141:805-816

21. Orikasa M, Matsui K, Oite T, Shimizu F (1988) Massive proteinuria in rats by a single intravenous injection of a monoclonal antibody. J Immunol 141:807-814

22. Kawachi H, Abrahamson DR, St. John PL, Goldstein DJ, Shia M, Matsui K et al (1995) Developmental expression of the nephritogenic antigen of monoclonal antibody 5-1-6. Am J Pathol 147:823-833

23. Mundel P, Kriz W (1995) Structure and function of podocytes: an update. Anat Embryol 192:385-397

24. Chang RLS, Deen WM, Robertson CR, Brenner BM (1975) Permselectivity of the glomerular capillary wall. III. Restricted transport of polyanions. Kidney Int 8:212-218

25. Rennke HG, Patel Y, Venkatachalam MA (1978) Glomerular filtration of proteins: clearance of anionic, neutral, and cationic horseradish peroxidase in the rat. Kidney Int 13:278-288

26. Mohos SC, Skoza L (1969) Glomerular sialoprotein. Science 164:1519-1521

27. Kanwar YS, Linker A, Farquhar MG (1980) Increased permeability of the glomerular basement membrane to ferritin after removal of glycosaminoglycans (heparin sulfate) by enzyme digestion. J Cell Biol 86:688-693

28. Mynderse LA, Hassell JR, Kleinman HK, Martin GR, Martinez-Hernandez A (1983) Loss of heparin sulfate proteoglycan from glomerular basement membrane of nephrotic rats. Lab Invest 48:292-

29. Huang TW, Langlois JC (1985) Podoendin: a new cell surface protein of the podocyte and endothelium. J Exp Med 162:245-267

30. Kerjaschki D, Sharkey DJ, Farquhar MG (1984) Identification and characterization of podocalyxin - the major sialoprotein of the renal glomerular epithelial cell. J Cell Biol 98: $1591-1596$

31. Thomas PE, Goyal M, Yang D-H, Wiggins RC (1996) GLEPP1 protein tyrosine phosphatase isoforms are sialoglycoproteins and are formed by alternative splicing, $\mathrm{N}$ - and Oglycosylation, and chondroitin sulfate attachment. J Am Soc Nephrol 6:815A

32. Mendrick D, Rennke HG (1988) Induction of proteinuria in the rat by a monoclonal antibody against SGP-115/107. Kidney Int 33:818-830

33. Mendrick DL, Rennke HG, Cotran RS, Springer T-A, Abbas AK (1983) Monoclonal antibodies against rat glomerular antigens: production and specificity. Lab Invest 49:107-117

34. Ozaki I, Ito Y, Fukatsu A, Suzuki N, Yoshida F, Watanabe Y et al (1990) A plasma mebrane antigen of rat glomerular epithelial cells: antigenic determinants involving N-linked sugar residues in a 140 kilodalton sialoglycoprotein of the podocytes. Lab Invest 63:707-716

35. Kerjaschki D (1994) Dysfunctions of cell biological mechanisms of visceral epithelial cell (podocytes) in glomerular diseases. Kidney Int 1994:300-313

36. Kershaw DB, Thomas PE, Wharram BL, Goyal M, Wiggins JE, Whiteside CI et al (1995) Molecular cloning, expression, and characterization of podocalyxin-like protein 1 from rabbit as a transmembrane protein of glomerular podocytes and vascular endothelium. J Biol Chem 270:29439-29446

37. Thomas PE, Wharram BL, Goyal M, Wiggins JE, Holzman LB, Wiggins RC (1994) Molecular cloning and characterization of a glomerular epithelial cell membrane protein-tyrosine phosphatase. J Biol Chem 269:19953-19961

38. Thomas PE, Goyal M, Wiggins RC (1996) Co-purification of PCLP1 with GLEPP1 protein-tyrosine phosphatase. J Am Soc Nephrol 7:1688A

39. Yang D-H, Goyal M, Sharif K, Kershaw DB, Thomas P, Dysko R et al (1996) Glomerular epithelial protein 1 and podocalyxin-like protein 1 in inflammatory glomerular disease (crescentic nephritis) in rabbit and man. Lab Invest 74: $571-584$

40. Orci L, Brown D, Amherdt M, Perrelet A (1982) Distribution of intramembrane particles and filipin-cholesterol com- 
plexes in plasma membranes of kidney. I. Corpuscle of Malphigi. Lab Invest 46:545-553

41. Saxen L (1987) Organogenesis of the kidney. In: Barlow PW, Green PB, Wylie CC (eds) Cambridge University Press, Cambridge (Developmental and Cell Biology Series)

42. Abrahamson DR (1991) Glomerulogenesis in the developing kidney. Sem Nephrol 11:375-389

43. Sorokin L, Ekblom P (1992) Development of tubular and glomerular cells of the kidney. Kidney Int 41:657-664

44. Reeves W, Calufield JP, Farquhar MG (1978) Differentiation of epithelial foot processes and filtration slits. Lab Invest 39: 90-100

45. Reeves WH, Kanwar YS, Farquhar MG (1980) Assembly of the glomerular filtration surface: differentiation of anionic sites in glomerular capillaries of newborn rat kidney. J Cell Biol 85:735-753

46. Nagata M, Yamaguchi Y, Ito K (1993) Loss of mitotic activity and the expression of vimentin in glomerular epithelial cells of developing human kidneys. Anat Embryol 187: 275-279

47. Mundel P, Gilbert P, Kriz W (1991) Podocytes in glomerulus of rat kidney express a characteristic $44 \mathrm{kD}$ protein. J Histochem Cytochem 39:1047-1056

48. Holthöfer H, Miettinen A, Lehto V-P, Lehtonen E, Virtanen I (1984) Expression of vimentin and cytokeratin type of intermediate filament proteins in developing and adult human kidneys. Lab Invest 50:552-559

49. Oosterwijk E, Van Muijen GNP, Ooserwijk-Wakka JC, Warnaar SO (1990) Expression of intermediate-size filaments in developing and adult human kidney and in renal cell carcinoma. J Histochem Cytochem 38:385-392

50. Pabst R, Sterzl RB (1983) Cell renewal of glomerular cell types in normal rats. An autoradiographic analysis. Kidney Int 24:626-631

51. Rasch R, Noorgard JOR (1983) Renal enlargement: comparative autoradiographic studies of $3 \mathrm{H}$-thymidine uptake in diabetic and uninephrectomized rats. Diabetologica 25: 280-287

52. Fries J, Sandstrom DJ, Meyer TW, Rennke HG (1989) Glomerular hypertrophy and epithelial cell injury modulate progressive glomerulosclerosis in the rat. Lab Invest 60: 205-218

53. Nagata M, Kriz W (1992) Glomerular damage after uninephrectomy in young rats. II. Mechanical stress of podocytes as a pathway to sclerosis. Kidney Int 42:148-160

54. Kriz W, Elger M, Kretzler M, Uiker S, Koeppen-Hagemann I, Tenschert $S$ et al (1994) The role of podocytes in the development of glomerular sclerosis. Kidney Int 45:S64-S72

55. Kriz W (1996) Progressive renal failure - inability of podocytes to replicate and the consequences for development of glomerulosclerosis. Nephrol Dial Transplant 11:1738-1742

56. Kriz W, Hähnel B, Rösener S, Elger M (1995) Long-term treatment of rats with FGF-2 results in focal segmental glomerulosclerosis. Kidney Int 48:1435-1450

57. Shankland SJ, Pippin J, Hugo C, Johnson RJ, Couser WG (1996) Lack of glomerular epithelial cell (GEC) proliferation in vivo is associated with increased expression of cyclin-kinase inhibitors. J Am Soc Nephrol 7:1720A

58. Bachmann S, Kriz W, Kuhn C, Franke WW (1983) Differentiation of cell types in the mammalian kidney by immunofluorescence microscopy using antibodies to intermediate filament proteins and desmoplakins. Histochem 77:365-394

59. Drenckhahn D, Franke RF (1988) Ultrastructural organization of contractile and cytoskeletal proteins in glomerular podocytes of chicken, rat and man. Lab Invest 59:673-682

60. Yaoita E, Kawasaki K, Yamamoto T, Kihara I (1990) Variable expression of desmin in rat glomerular epithelial cells. Am J Pathol 136:899-908

61. Huber G, Matus A (1990) Microtubule-associated protein 3 (MAP3) expression in non-neuronal tissues. J Cell Sci 95: 237-246
62. Parysek LM, Wolosewick JJ, Olmsted JB (1984) MAP4: a microtubule-associated protein specific for a subset of tissue microtubules. J Cell Biol 99:2287-2296

63. Adler S (1992) Characterization of glomerular epithelial cell matrix receptors. Am J Pathol 141:571-578

64. Kerjaschki D, Ojha PP, Susani M, Horvat R, Binder S, Hovorka $A$ et al (1989) A $\beta \exists 1$-integrin receptor for fibronectin in human kidney glomeruli. Am J Pathol 134:481-489

65. Korhonen M, Ylanne J, Laitinen L, Virtanen I (1990) The $\alpha \exists 1-\alpha \exists 5$ subunits of integrins are characteristically expressed in distinct segments of developing and adult human nephron. J Cell Biol 111:1245-1254

66. Korhonen M, Ylanne J, Laitinen L, Virtanen I (1990) Distribution of $\beta \exists 1$ and $\beta \exists 3$ integrins in human fetal and adult kidney. Lab Invest 62:616-625

67. Kriz W, Elger M, Mundel P, Lemley K (1995) Structure-stabilizing forces in the glomerular tuft. J Am Soc Nephrol 5: 1731-1739

68. Vernier RL, Papermaster BW, Good RA (1958) Aminonucleoside nephrosis. I. Electron microscopic study of the renal lesion in rats. J Exp Med 109:115-126

69. Ito K, Ger YC, Kawamura S (1986) Actin filament alterations in glomerular epithelial cells of adriamycin-induced nephrotic rats. Acta Pathol Jpn 36:253-260

70. Farquhar MG, Vernier RL, Good RA (1957) An electron microscopic study of the glomerulus in nephrosis, glomerulonephritis and lupus erythematosus. J Exp Med 106:649-660

71. Kanwar YS, Rosenzweig LJ (1982) Altered glomerular permeability as a result of focal detachment of the visceral epithelium. Kidney Int 21:565-574

72. Whiteside C, Prutis K, Cameron R, Thompson J (1989) Glomerular epithelial detachment, not reduced charge density, correlates with proteinuria in adriamycin and puromycin nephrosis. Lab Invest 61:650-660

73. Messina A, Davies DJ, Dillane PC, Ryan GB (1987) Glomerular epithelial abnormalities associated with the onset of proteinuria in aminonucleoside nephrosis. Am J Pathol 126: 220-229

74. Laurens W, Battaglia C, Foglieni C, De Vos R, Malanchini B, Van Damme B et al (1995) Direct podocyte damage in the single nephron leads to albuminuria in vivo. Kidney Int 47 : $1078-1086$

75. Guasch A, Myers BD (1994) Determinants of glomerular hypofiltration in nephrotic patients with minimal change nephropathy. J Am Soc Nephrol 4:1571-1581

76. Blantz RC, Gabbai FB, Peterson O, Wilson CB, Kihara I, Kawachi H et al (1994) Water and protein permeability is regulated by the glomerular epithelial slit diaphragm. J Am Soc Nephrol 4:1957-1964

77. Drummond MC, Deen WM (1994) Structural determinants of glomerular hydraulic permeability. Am J Physiol 266: F1-F12

78. Kurihara H, Anderson JM, Farquhar MG (1995) Increased Tyr phosphorylation of Z0-1 during modification of tight junctions between glomerular foot processes. Am J Physiol 37:F514-F524

79. Kerjaschki D (1978) Polycation-induced dislocation of slit diaphragms and formation of cell junctions in rat kidney glomeruli: the effects of low temperature, divalent cations, colchicine, and cytochalasin B. Lab Invest 39:430-440

80. Seiler MW, Venkatachalam MA, Cotran RS (1975) Glomerular epithelium: structural alterations induced by polycations. Science 189:390-393

81. Seiler MW, Rennke HG, Venkatachalam MA, Cotran RS (1977) Pathogenesis of polycation induced alterations ("fusion") of glomerular epithelium. Lab Invest 36:48-61

82. Hunsicker LG, Shearer TP, Shaffer SJ (1981) Acute reversible proteinura induced by infusion of polycation hexadimethrine. Kidney Int 20:7-17

83. Bridges CRJ, Rennke HG, Deen WM, Troy JL, Brenner BM (1991) Reversible hexadimethrine-induced alterations in 
glomerular structure and permeability. J Am Soc Nephrol 1: 1095-1108

84. Michael AF, Blau E, Vernier RL (1970) Glomerular polyanion: alteration in aminonucleoside nephrosis. Lab Invest 23 649-657

85. Caulfield JP, Farquhar MG (1978) Loss of anionic sites from the glomerular basement membrane in aminonucleoside nephrosis. Lab Invest 39:505-

86. Mahan JD, Sisson-Ross S, Vernier RL (1986) Glomerular basement membrane anionic charge site changes early in aminonucleoside nephrosis. Am J Pathol 125:393-401

87. Groggel GC, Hovingh P, Border WA, Linker A (1987) Changes in glomerular heparin sulfate in puromycin aminonucleoside nephrosis. Am J Pathol 128:521-527

88. Kanwar YS, Jakubowski ML (1984) Unaltered anionic sites of glomerular basement membrane in aminonucleoside nephrosis. Kidney Int 25:613-618

89. Kerjaschki D, Vernillo AT, Farquhar MG (1985) Reduced sialylation of podocalyxin - the major sialoprotein of the rat kidney glomerulus - in aminonucleoside nephrosis. Am J Pathol 118:343-349

90. Yoshioka T, Ichikawa I, Fogo A (1991) Reactive oxygen metabolites cause massive, reversible proteinuria and glomerular sieving defect without apparent ultrastructural abnormality. J Am Soc Nephrol 2:902-912

91. Mitchison T, Klymkowsky M (1994) The cytoskeleton. In: Alberts B, Bray D, Lewis J et al (eds) Molecular biology of the cell, 3rd edn. Garland, New York, pp 834-847

92. Andrews PM, Bates SB (1984) Filamentous actin bundles in the kidney. The Anatomical Record 210:1-9

93. Vasmant D, Maurice M, Feldmann G (1984) Cytoskeletal ultrastructure of podocytes and glomerular endothelial cells in man and in the rat. Anat Rec 210:17-24

94. Hoffmann EO (1982) The detection of effaced podocytes by high resolution light microscopy. Am J Clin Pathol 78: $508-510$

95. Whiteside CI, Cameron R, Munk S, Levy J (1993) Podocytic cytoskeletal disaggregation and basement-membrane detachment in puromycin aminonucleoside nephrosis. Am J Pathol 142:1641-1653

96. Lachapelle M, Bendayan M (1991) Contractile proteins in podocytes: immunochemical localization of actin and alphaactinin in normal and nephrotic rat kidneys. Virchows Archiv B Cell Pathol 60:105-111

97. Shirato I, Sakai T, Kimura K, Tomino Y, Kriz W (1996) Cytoskeletal changes in podocytes associated with foot process effacement in Masugi nephritis. Am J Pathol 148:1283-1296

98. Otey CA, Vasquez GB, Burridge K, Erickson BW (1993) Mapping of the alpha-actinin binding site within the beta 1 integrin cytoplasmic domain. J Biol Chem 268:21193-21197

99. Smoyer WE, Mundel P, Gupta A, Welsh MJ (1997) Podocyte $\alpha \exists$-actinin induction precedes foot process effacement in experimental nephrotic syndrome. Am J Physiol (in press)

100. Smoyer WE, Gupta A, Mundel P, Ballew JD, Welsh MJ (1996) Altered expression of glomerular heat shock protein 27 in experimental nephrotic syndrome. J Clin Invest 97:2697-2704

101. Lindquist S, Graig EA (1988) The heat shock proteins. Annu Rev Genet 22:631-677

102. Rothman JE (1989) Polypeptide chain binding proteins: catalysts of protein folding and related processes in cells. Cell 59:591-601

103. Welch WJ (1992) Mammalian stress response: cell physiology, structure/function of stress proteins, and implications for medicine and disease. Physiol Rev 72:1063-1081

104. Ross WR, Bertrand WS, Morrison AR (1992) Identification of a processed protein related to the human chaperonins (hsp60) protein in mammalian kidney. Biochem Biophys Res Commun 185:683-687

105. Wakui H, Itoh H, Tashima R, Nakamoto Y, Miura AB (1992) Purification of a mature form of $60 \mathrm{kDa}$ heat-shock protein (chaperonin homolog) from porcine kidney and its partial amino acid sequence. Int J Biochem 24:1507-1510
106. Komatsuda A, Wakui H, Imai H, Nakamoto Y, Miura AB, Itoh $\mathrm{H}$ et al (1992) Renal localization of the constitutive 73$\mathrm{kDa}$ heat-shock protein in normal and PAN rats. Kidney Int 41:1204-1212

107. Emami A, Schwartz JH, Borkan SC (1991) Transient ischemia or heat stress induces a cytoprotectant protein in rat kidney. Am J Physiol 260:F479-F485

108. Matsubara O, Kasuga T, Marumo F, Itoh H, Tashima $\mathrm{Y}$ (1990) Localization of the $90-\mathrm{kDa}$ heat shock protein in the kidney. Kidney Int. 38:830-834

109. Lovis C, Mach F, Donati RA, Bonventre JV, Polla BS (1994) Heat shock proteins and the kidney. Renal Failure 16: 179-192

110. Muller E, Neuhofer W, Ohno A, Rucker S, Thurau K, Beck F-X (1996) Heat shock proteins HSP25, HSP60, HSP72, HSP73 in isoosmotic cortex and hyperosmotic medulla of rat kidney. Eur J Physiol 431:608-617

111. Medina R, Cantley L, Spokes K, Epstein FH (1996) Effect of water diuresis and water restriction on expression of HSPs-27, -60 and -70 in rat kidney. Kidney Int 50:1191-1194

112. Landry J, Chretien P, Lambert H, Hickey E, Weber LA (1989) Heat shock resistance conferred by expression of the human HSP27 gene in rodent cells. J Cell Biol 109:7-15

113. Huot J, Roy G, Lambert H, Chretien P, Landry J (1991) Increased survival after treatments with anticancer agents of Chinese hamster cells expressing the human Mr 27,000 heat shock protein. Cancer Res 51:5245-5252

114. Jakob U, Gaestel M, Engel K, Buchner J (1993) Small heat shock proteins are molecular chaperones. J Biol Chem 268: $1517-1520$

115. Lavoie JN, Gingras-Breton G, Tanguay RM, Landry J (1993) Induction of Chinese hamster hsp27 gene expression in mouse cells confers resistance to heat shock. J Biol Chem 268:3420-3429

116. Ciocca DR, Oesterreich S, Chamness GC, McGuire WL, Fuqua SAW (1993) Biological and clinical implications of heat shock protein 27000 (Hsp27): a review. J Natl Cancer Inst. 85:1558-1570

117. Arrigo AP, Landry J (1994) Expression and function of the low-molecular-weight heat shock proteins. In: Morimoto RI, Tissieres A, (eds) The biology of heat shock proteins and molecular chaperones. Cold Spring Harbor Laboratory Press, Plainview, pp 335-373

118. Mehlen P, Preville X, Chareyron P, Briolay J, Klemenz R, Arrigo AP (1995) Constitutive expression of human hsp27, Drosophila hsp27 or human $\alpha \exists \mathrm{B}$-crystallin confers resistance to TNF- and oxidative stress-induced cytotoxicity in stably transfected murine L929 fibroblasts. J Immunol 154: 363-374

119. Miron T, Wilchek M, Geiger B (1988) Characterization of an inhibitor of actin polymerization in vinculin-rich fraction of turkey gizzard smooth muscle. Eur J Biochem 178: 543-553

120. Miron T, Wilchek M, Geiger B (1991) A 25 kD inhibitor of actin polymerization is a low molecular mass heat shock protein. J Cell Biol 114:255-261

121. Benndorf R, Hayeb K, Ryazantsev S, Wieske M, Behlke J, Lutsch G (1994) Phosphorylation and supramolecular organization of murine small heat shock protein HSP25 abolish its actin polymerization-inhibiting activity. J Biol Chem 269: 20780-20784

122. Lavoie JN, Lambert H, Hickey E, Weber LA, Landry J (1995) Modulation of cellular thermoresistance and actin filament stability accompanies phosphorylation-induced changes in the oligomeric structure of heat shock protein 27. Molec Cell Biol 15:505-516

123. Lavoie J, Hickey E, Weber LA, Landry J (1993) Modulation of actin microfilament dynamics and fluid phase pinocytosis by phosphorylation of heat shock protein 27. J Biol Chem 268:24210-24214

124. Freshney NW, Rawlinson L, Guesdon F, Jones E, Cowley S, Hsuan J et al (1994) Interleukin-1 activates a novel protein 
kinase cascade that results in the phosphorylation of hsp27. Cell 78:1039-1049

125. Rollet E, Lavoie JN, Landry J, Tanguay RM (1992) Expression of Drosophila's $27 \mathrm{kDa}$ heat shock protein into rodent cells confers thermal resistance. Biochem Biophys Res Commun 185:116-120

126. Mehlen P, Briolay J, Smith L, Diaz-Latoud C, Fabre N, Pauli $\mathrm{D}$ et al (1993) Analysis of the resistance to heat and hydrogen peroxide stresses in COS cells transiently expressing wild type or deletion mutants of the Drosophila 27-kDa heat shock protein. Eur J Biochem 215:277-284

127. Wu W, Welsh MJ (1996) Expression of the 25-kDa heatshock protein (HSP27) correlates with resistance to the toxicity of cadmium chloride, mercuric chloride, cis-platinum(II)-diammine dichloride, or sodium arsenite in mouse embryonic stem cells transfected with sense or antisense HSP27 cDNA. Toxicol Appl Pharmacol 141:330-339

128. Masugi M (1934) Ueber die experimentelle Glomerulonephritis durch das specifischen Antinierenserum. Beitr Pathol Anat Alg Path 92:429-466

129. Kay CF (1942) The mechanism of a form of glomerulonephritis. Nephrotoxic nephritis in rabbits. Am J Med Sci 204: 483-490

130. Cochrane CG, Unanue ER, Dixon FJ (1965) A role of polymorphonuclear leukocytes and complement in nephrotoxic nephritis. J Exp Med 122:99-116

131. Kondo Y, Shigematsu H (1972) Cellular aspects of rabbit Masugi nephritis. I. Cell kinetics in recoverable glomerulonephritis. Virchows Arch B Pathol Anat 10:40-50

132. Cosio FG (1992) Cell-Matrix adhesion receptors: relevance to glomerular pathology. Am J Kidney Dis 20:294-305

133. Cybulsky AV, Carbonetto S, Huang Q, McTavish AJ, Cyr MD (1992) Adhesion of rat glomerular epithelial cells to extracellular matrices: role of $\beta \exists 1$ integrins. Kidney Int 42:1099-1106
134. Baraldi A, Furci L, Zambruno G, Rubbiani E, Annessi G, Lusvarghi E (1992) Very late activation-3 integrin is the dominant beta 1 integrin on the glomerular capillary wall: an immunofluorescence study in nephrotic syndrome. Nephron 62:382-388

135. Baraldi A, Zambruno G, Furci L, Manca V, Vaschieri C, Lusvarghi E (1994) Beta-1 integrins in the normal human glomerular capillary wall: an immunoelectron microscopic study. Nephron 66:295-301

136. Adler S (1992) Integrin receptors in the glomerulus: potential role in glomerular injury. Am J Physiol 262:F697-F704

137. Kreidberg JA, Donovan MJ, Goldstein SL, Rennke H, Shepherd K, Jones RC et al (1996) Alpha 3 beta 1 integrin has a crucial role in kidney and lung organogenesis. Development 122:3537-3547

138. Adler S, Sharma R, Savin VJ, Abbi R, Eng B (1996) Alteration of glomerular permeability to macromolecules induced by cross-linking of beta 1 integrin receptors. Am J Pathol 149:987-996

139. Adler S, Eng B (1995) Proteinuria induced by antibodies reactive with beta 1 integrins. J Am Soc Nephrol 6:860A

140. Shikata K, Hirofumi M, Morioka S, Kashitani T, Hirata K, Ota Z et al (1995) Distribution of extracellular matrix receptors in various forms of glomerulonephritis. Am J Kid Dis 25:680-688

141. Nevins TE, Gaston T, Basgen JM (1984) Quantitative indexes of aminonucleoside-induced nephrotic syndrome. Am J Pathol 117:30-36

142. Cosio FG, Sedmak DD, Nahman NSJ (1990) Cellular receptors for matrix proteins in normal human kidney and human mesangial cells. Kidney Int 38:886-895 